\title{
Rats do show primacy and recency effects in memory for lists of spatial locations: A reply to Gaffan
}

\author{
RAYMOND P. KESNER, ANDREA A. CHIBA, and PAMELA JACKSON-SMITH \\ University of Utah, Salt Lake City, Utah
}

\begin{abstract}
It has been demonstrated that rats display both primacy and recency effects in list-learning experiments for both item- and order-recognition memory for spatial location information. Contrary to a suggestion made by Gaffan (1992) that previous demonstrations of primacy effects in rats are not valid due to statistical and methodological problems, we show that (1) it is not likely that our results are due to experimenter bias and/or nonindependence of trials, (2) primacy and recency effects are obtained whether or not one uses a training criterion, and (3) when many of the published reports from our laboratory are combined, the number of subjects and trials are sufficient to evaluate the validity of primacy and recency effects in list-learning experiments.
\end{abstract}

In recent years many experiments have been conducted to determine what rats can remember about lists of spatial or nonspatial items. When probes are used to test memory for items occupying a specific position within a list, it has been reported that rats display both recency effects (better memory for items at the end of the list than for items in the middle of the list) and primacy effects (better memory for items at the beginning of the list than for items in the middle of the list) (Johnson \& Kesner, in press; Kesner, Crutcher, \& Beers, 1988; Kesner, Crutcher, \& Measom, 1986; Kesner, Crutcher, \& Omana, 1990; Kesner \& Holbrook, 1987). It was recently proposed, however, that there has not yet been a convincing demonstration that rats can display both primacy and recency effects (Gaffan, 1992). Although the presence of recency effects is widely accepted, Gaffan suggested that previous demonstrations of primacy effects displayed by rats are not valid, due to statistical and methodological problems. She proposed that the variance in mean percentcorrect performance in these studies was lower than that predicted by the binomial distribution, especially in orderrecognition memory tasks. Gaffan argued that these variances are too low, due to (1) a nonindependence of trials and/or subjects, (2) experimenter bias, (3) the selection of data through the use of a training criterion, or (4) an insufficient number of observations per data point based on number of trials and number of subjects.

We suggest that data that have been collected over an 8-year period in our laboratory do, in fact, support the presence of primacy effects in rats for both item- and order-recognition memory of spatial locations. Given that we are most familiar with our own data, and that Gaffan (1992) did not request information concerning variabil-

Reprint requests should be sent to R. P. Kesner, Department of Psychology, University of Utah, Salt Lake City, UT 84112. We thank Charles Shimp for critical reading of the manuscript. ity in our published data, we will summarize our own research and provide statistical analyses that are based on data not available to Gaffan. Furthermore, we will demonstrate that (1) it is not likely that our results are due to experimenter bias and/or nonindependence of trials, (2) primacy and recency effects were obtained whether we used a training criterion or not, and (3) when many of the published reports from our laboratory are combined, the number of subjects and trials are sufficient to determine the validity of primacy and recency effects in list-learning experiments.

We have primarily used two different paradigms. The first paradigm employed an item-recognition measure for a list of five spatial locations on an eight-arm radial maze. Each item memory trial (one per day) consisted of a study phase and a test phase. During the study phase, each rat was allowed to visit each of five arms once, in an order that was pseudorandomly selected for that trial. Each fivearm sequence was presented to the rat by the opening (one at a time) of Plexiglas doors that were located at the entrance of each arm. Immediately after the rat had received reinforcement from the last of the five arms, the test phase began. During the test phase of each trial, the rat was retained on the central platform of the maze, and an opaque cylinder was placed around the rat in order to obscure its view of the maze. Two doors were then opened simultaneously. One of the doors led to an arm that had been visited during the study phase of that trial, and the other door led to a novel arm for that trial. In order to collect an additional reinforcement, the rat had to choose the arm that had been visited during the study phase of the trial (win-stay).

The second paradigm employed an order-recognition measure for a list of eight spatial locations on an eightarm radial maze. For the order memory task, each trial (one per day) consisted of a study phase and a test phase. During the study phase, each rat was allowed to visit each 
of eight arms once, in an order that was pseudorandomly selected for that trial. Each eight-arm sequence was presented to the rat by the opening (one at a time) of Plexiglas doors located at the entrance of each arm. Immediately after the rat had received reinforcement from the last of the eight arms, the test phase began. During the test phase of each trial, the rat was retained on the central platform of the maze, and an opaque cylinder was placed around the rat in order to obscure its view of the maze. At this time, two doors, both of which had been visited during the study phase, were simultaneously opened. In order to receive an additional reinforcement, the rats had to choose the arm that had been visited earlier in the sequence. Pairs of arms were selected as test arms on a pseudorandom basis, including the first and second, fourth and fifth, or seventh and eighth arms visited during the study phase.

In order to ensure that there was independence among subjects, the maze was cleaned between subjects, and on a given day each subject was presented with a different study-phase sequence and probed for different serial positions in the test phase. Thus, potential nonindependence of subjects is not likely to be a concern in evaluating the results of the item- and order-recognition experiments.

It was necessary to provide pseudorandom sequences for the study phases, because each test phase had to consist of arms that were spatially no farther than two apart, in order to eliminate body position as a determining factor in response choice. An equal number of tests for each serial position were given within a block of trials as well. Therefore, it was not possible to provide for complete independence between trials, as required for an analysis of the data using a binomial distribution. Given that on any one trial there is a probability of .69 that the specific arms to be selected for the test phase are adjacent or separated by one arm, it is not likely that the rats could develop a complex probability rule to anticipate possible test pairs.

Over an 8-year period, at least 20 different experimenters have been involved in training rats in item- and order-recognition tasks. A number of these experimenters were undergraduates who had no knowledge of serialposition curves and therefore had no prior expectations. Given that the outcome has been consistent throughout, it is unlikely that the emergence of a primacy effect can be attributed to experimenter bias.

We have reanalyzed our data to test the statistical arguments presented by Gaffan (1992). The use of a test measure involving a choice between two alternatives gives rise to a binomial distribution of scores. The variance of the binomial distribution is related to its mean. To calculate the variance, one can use the formula $T p(1-p)$, where $T$ represents the number of trials per subject per data point, and $p$ is the group mean probability of correct performance at that point. It is then possible to compare the expected variance from a binomial distribution with the observed variance of the subject population by calculating the ratio of observed to expected variance. This ratio should approximate 1 . One can then determine whether the observed ratio is significantly different from 1 by using
Table 1

Item-Recognition Memory: Preoperative Performance of 67 Rats Based on a Criterion of $\mathbf{7 5 \%}$ or Better Performance for the First and Last Serial Positions

\begin{tabular}{ccccc}
\hline $\begin{array}{c}\text { Trials per } \\
\text { Data Point }\end{array}$ & $\begin{array}{c}\text { Serial } \\
\text { Position }\end{array}$ & $\begin{array}{c}\text { Mean Percent } \\
\text { Correct }\end{array}$ & $\begin{array}{c}\text { Observed/Expected } \\
\text { Variance }\end{array}$ & $\chi^{2}$ \\
\hline 8 & 1 & 89.4 & 1.08 & 71.3 \\
8 & 2 & 82.2 & 2.06 & $136.0^{*}$ \\
8 & 3 & 82.4 & 2.09 & $137.9^{*}$ \\
8 & 4 & 78.4 & 2.06 & $136.0^{*}$ \\
8 & 5 & 86.0 & .84 & 55.4 \\
\hline
\end{tabular}

*Variance too high.

a chi-square statistical test. The chi-square value is derived by multiplying the obtained ratio by $N-1$, where $N$ represents the number of subjects. The derived chisquare value is then tested to see whether it differs significantly from that occurring by chance. A confidence level of $95 \%$ is then used to determine whether the chisquare value is either greater or smaller than the value expected. Thus, in order to address the issue of acceptable observed variances, for each experiment we will present the total number of subjects, number of trials per data point, mean percent-correct performance, observed/ expected variance score, and chi-square value for each serial position.

Using the item-recognition paradigm, we have trained 67 rats preoperatively across four studies to a criterion of $75 \%$ correct or better performance for both the first and last positions within the five-item list (Johnson \& Kesner, in press; Kesner et al., 1988; Kesner et al., 1990; Kesner \& Holbrook, 1987). The means, observed/expected variance ratios, and chi-square values are shown in Table 1. Notice that the variances are not too low; rather, three of the variances are too high. It should also be noted that all rats learn the item-recognition task, and that all rats display high levels of performance for the first and last serial positions within a sequence. Furthermore, with overtraining, the animals eventually perform well $(90 \%$ or better) for all serial positions.

Twenty of the animals that were preoperatively trained to a criterion were given a sham operation or a vehicle injection, followed by a week of recovery. These animals were then given an additional set of 40 trials. The animals were not retrained to a criterion. The means, observed/expected variance ratios, and chi-square values are shown in Table 2 . Note that only one score had too low of a variance (Position 3, postoperative), but none of the other chi-square values for other positions, including Positions 1 and 5, were found to differ significantly from chance. An analysis of variance (ANOVA) using surgery phase (pre- vs. postsurgery) and serial position as withinsubject factors revealed a significant main effect of serial position $[F(4,76)=6.7, p<.0001]$, but no significant main effect of surgery phase $[F(1,19)=.16, p=.69]$ and no significant surgery phase $\times$ serial position interaction $[F(4,76)=1.4, p=.24]$. A Newman-Keuls post hoc analysis of serial position revealed that mean percentcorrect performance on the first serial position was significantly higher than that on the second, third, or fourth 
Table 2

Item-Recognition Memory: Preoperative Performance of 20 Rats Based on a Criterion of $75 \%$ or Better Performance for the First and Last Serial Positions and Postoperative Performance of Sham-Operated or Vehicle-Injected Rats Based on 40 Postoperative Trials (No Set Criterion)

\begin{tabular}{ccccc}
$\begin{array}{c}\text { Trials per } \\
\text { Data Point }\end{array}$ & $\begin{array}{c}\text { Serial } \\
\text { Position }\end{array}$ & $\begin{array}{c}\text { Mean Percent } \\
\text { Correct }\end{array}$ & $\begin{array}{c}\text { Observed/Expected } \\
\text { Variance }\end{array}$ & $\chi^{2}$ \\
\cline { 1 - 4 } & \multicolumn{4}{c}{ Preoperation } \\
8 & 1 & 85.8 & 1.08 & \\
8 & 2 & 78.3 & 2.03 & 38.5 \\
8 & 3 & 80.8 & 2.72 & 51.7 \\
8 & 4 & 78.9 & 1.92 & 36.5 \\
8 & 5 & 82.7 & .66 & 12.5 \\
& & Postoperation & & \\
8 & 1 & 89.0 & .62 & 11.8 \\
8 & 2 & 80.3 & .95 & 18.1 \\
8 & 3 & 76.2 & .44 & $8.4 *$ \\
8 & 4 & 74.7 & 1.13 & 21.5 \\
8 & 5 & 85.0 & .91 & 17.4 \\
\hline
\end{tabular}

*Variance too low.

positions $(p<.05)$. The performance on the last position was significantly higher than that on the fourth position $(p<.05)$.

Thus, there are clear primacy and recency effects, even when no postsurgical performance criterion was used. To elaborate further on the importance or lack of importance of variability when using a training criterion, we present the means, observed/expected variance ratios, and chisquares for DiMattia and Kesner's (1984) study (see Table 3). These means are of particular interest, given that we did not presurgically train the subjects to a criterion in this study. Notice that none of the obtained variances was lower than that expected by chance, although two of the five variances were higher than that expected by chance. Thus, primacy effects are observed, even if one does not train subjects to a performance criterion. In summary, based on a total of 83 subjects, whether one uses a training criterion or not, there is a clear primacy effect in itemrecognition list learning. We believe that the number of subjects involved in these studies represents a sample that is large enough to give statistical power to the validity of a primacy effect in item-recognition memory for spatial locations.

Are there any replications of primacy and recency effects in rats in item-recognition memory tasks using a win-stay procedure? To our knowledge there are no published reports of a failure to replicate the above-mentioned

Table 3

Item-Recognition Memory: Preoperative Performance of 16 Rats Based on a Fixed Set of Acquisition Trials (No Set Criterion)

\begin{tabular}{ccccc}
\hline $\begin{array}{c}\text { Trials per } \\
\text { Data Point }\end{array}$ & $\begin{array}{c}\text { Serial } \\
\text { Position }\end{array}$ & $\begin{array}{c}\text { Mean Percent } \\
\text { Correct }\end{array}$ & $\begin{array}{c}\text { Observed/Expected } \\
\text { Variance }\end{array}$ & $\chi^{2}$ \\
\hline 8 & 1 & 84.5 & .93 & 14.0 \\
8 & 2 & 70.0 & 2.82 & $42.3^{*}$ \\
8 & 3 & 61.8 & 1.54 & 23.1 \\
8 & 4 & 78.4 & 1.78 & $26.7^{*}$ \\
8 & 5 & 80.6 & 1.46 & 21.9 \\
\hline
\end{tabular}

*Variance too high. results. As a matter of fact, Harper, Dalrymple-Alford, and McLean $(1992,1993)$ reported both primacy and recency effects when they used a win-stay rule and a list length of seven spatial locations in a 12-arm maze. Other studies of item-recognition memory in rats either did not probe for serial-position effects (Maki, Beatty, \& Clouse, 1984) or used a win-shift procedure (Bolhuis \& van Kampen, 1988; DiMattia \& Kesner, 1984; Kesner \& Holbrook, 1987; Roberts \& Smythe, 1979). In the case of the win-shift procedure, all of the above-mentioned studies report the presence of a recency effect but not a primacy effect when short delays $(10-30 \mathrm{sec})$ were interposed between the study and test phases. Thus, there is complete agreement among the four studies. However, Bolhuis \& van Kampen have shown that with long delays $(16 \mathrm{~min})$, the recency effect becomes smaller and a primacy effect appears. We have shown similar results in our lab with win-shift-trained rats. When a 5-min delay was imposed between the study and test phase, the win-shift animals showed significant improvement at all five serial positions, including the primacy position. We have proposed that the tendency of the win-stay, but not the win-shift, procedure to generate primacy effects might be due to the degree of elaborative or effortful processing (Hasher \& Zacks, 1979) that the task requires. The notion that a win-stay procedure requires more elaborative processing could account for the fact that win-staytrained animals take considerably longer to learn the rule than do win-shift-trained animals.

Other researchers have demonstrated a similar training disparity between the two conditions (Cole, Hainsworth, Kamil, Mercier, \& Wolf, 1982; Gaffan \& Davies, 1981; Olton, Handleman, \& Walker, 1981; Olton \& Schlosberg, 1978). This training disparity suggests the possibility that the win-stay strategy is more difficult for rats to learn and therefore requires more effortful processing. Hasher and Zacks (1979) argued that one of the means by which a given process can become an automated one is via heredity. Rats may be hereditarily predisposed to use the win-shift strategy (Olton et al., 1981; Olton \& Schlosberg, 1978). Therefore, the win-shift approach may have been relegated to an automatic process in this species. Hence, if the win-shift animals are relying on automatic processing and they show no primacy effects, it is possible that the main determinant of primacy effects in a list-learning situation is whether or not the animals must engage in elaborative processing in order to perform the task. Therefore, we propose that the primacy component of the serial-position curve is present only if the mnemonic task places a sufficient load on the cognitive system so as to necessitate nonautomatic, effortful processing. The results obtained by Bolhuis and van Kampen can also be explained in a similar manner, in that the task was made ostensibly more difficult by the imposition of longer delays, so that effortful processing rather than automatic processing was required to remember items within the list, and thus primacy effects emerged.

The order-recognition memory task is difficult for rats to learn. Based on 80 subjects trained in the order- 
recognition memory task, $84 \%$ of the rats displayed both primacy and recency effects. Furthermore, very few of the rats ever performed the task at $100 \%$ correct for the 1-2 or 7-8 positions. We have analyzed the observed/ expected variance ratios and chi-squares for the eight-arm order-recognition task (Kesner, Measom, Forsman, \& Holbrook, 1984) for rats that were trained to a criterion of $75 \%$ or better performance for the 1-2 and 7-8 positions within the eight-item list. As can be observed in Table 4 , the chi-square values for the 1-2 and 7-8 serial positions were significantly lower than those expected by chance. In that study, 5 animals did not reach criterion performance and were not included in the analysis. If, however, we do include the data for these 5 subjects, we still obtain a significant main effect for serial position, on the basis of a one-way ANOVA $[F(2,58)=41.5, p<$ $.0001]$. A post hoc Newman-Keuls test for serial position indicated that performance on the 1-2 and the 7-8 positions was significantly higher than that on the 4-5 serial position $(p<.01)$. In addition, it can be seen in Table 5 that the variances are neither higher nor lower than those expected by chance when all the trained rats were included.

When rats are trained to a criterion on the order task, is there a high probability that the variances will be lower than those expected to occur by chance? In order to address this question, we analyzed the data from 15 randomly selected rats that were trained to a criterion of $75 \%$ or better performance for the 1-2 and 7-8 positions within the eightitem list in the eight-arm order-recognition task. Each rat was subsequently given a sham operation or a vehicle injection, followed by a week of recovery, and was then given an additional set of 24 trials. The animals were not postoperatively retrained to a criterion (Kesner et al., 1986; Kesner et al., 1990; Kesner \& Holbrook, 1987). The results of preoperative and postoperative training, shown in Table 6 , indicate that none of the variances was different from those expected by chance. A repeated measures

Table 4

Order-Recognition Memory: Preoperative Performance of 25 Rats Based on a Criterion of $75 \%$ or Better Performance for the 1-2 and 7-8 Positions

\begin{tabular}{ccccc}
\hline $\begin{array}{c}\text { Trials per } \\
\text { Data Point }\end{array}$ & $\begin{array}{c}\text { Serial } \\
\text { Position }\end{array}$ & $\begin{array}{c}\text { Mean Percent } \\
\text { Correct }\end{array}$ & $\begin{array}{c}\text { Observed/Expected } \\
\text { Variance }\end{array}$ & $\chi^{2}$ \\
\hline 8 & $1-2$ & 78.4 & .54 & $13.0^{*}$ \\
8 & $4-5$ & 50.3 & 1.11 & 26.6 \\
8 & $7-8$ & 78.1 & .33 & $7.9^{*}$ \\
\hline
\end{tabular}

*Variance too low.

Table 5

Order-Recognition Memory: Preoperative Performance of 30 Rats, 5 of Which Did Not Obtain Criterion of $75 \%$ or Better Performance for the 1-2 and 7-8 Positions

\begin{tabular}{ccccc}
\hline $\begin{array}{c}\text { Trials per } \\
\text { Data Point }\end{array}$ & $\begin{array}{c}\text { Serial } \\
\text { Position }\end{array}$ & $\begin{array}{c}\text { Mean Percent } \\
\text { Correct }\end{array}$ & $\begin{array}{c}\text { Observed/Expected } \\
\text { Variance }\end{array}$ & $\chi^{2}$ \\
\hline 8 & $1-2$ & 77.0 & .70 & 20.3 \\
8 & $4-5$ & 50.7 & 1.00 & 29.0 \\
8 & $7-8$ & 76.0 & .67 & 19.4 \\
\hline
\end{tabular}

Table 6

Order-Recognition Memory: Preoperative Performance of 15 Rats Based on a Criterion of $75 \%$ or Better Performance for the 1-2 and 7-8 Positions, and Postoperative Performance of Sham-Operated or Vehicle-Injected Rats Based on 24 Postoperative Trials (No Set Criterion)

\begin{tabular}{ccccr}
$\begin{array}{c}\text { Trials per } \\
\text { Data Point }\end{array}$ & $\begin{array}{c}\text { Serial } \\
\text { Position }\end{array}$ & $\begin{array}{c}\text { Mean Percent } \\
\text { Correct }\end{array}$ & $\begin{array}{c}\text { Observed/Expected } \\
\text { Variance }\end{array}$ & \multicolumn{1}{c}{$\chi^{2}$} \\
\hline \multicolumn{5}{c}{ Preoperation } \\
8 & $1-2$ & 81.8 & .56 & 7.8 \\
8 & $4-5$ & 55.3 & .87 & 12.2 \\
8 & $7-8$ & 80.1 & .51 & 7.1 \\
& & Postoperation & & \\
8 & $1-2$ & 74.4 & 1.63 & 22.8 \\
8 & $4-5$ & 52.8 & .69 & 9.7 \\
8 & $7-8$ & 76.1 & .53 & 7.4 \\
\hline
\end{tabular}

ANOVA with surgery phase (pre- vs. postsurgery) and serial position as within-subject factors revealed a significant main effect of serial position $[F(2,28)=42.4, p<$ $.0001]$, but no significant main effect of surgery phase $[F(1,14)=3.97, p=.066]$ and no significant surgery phase $\times$ serial position interaction $[F(2,28)=.34, p=$ $.72]$. A post hoc Newman-Keuls analysis of serial position revealed that performance on the 1-2 and the 7-8 positions was significantly higher than that on the 4-5 serial position $(p<.01)$.

Thus, primacy and recency effects are present even when no training criterion was employed. We attribute the apparent reduction in variance that was below that expected by chance for the end serial positions (see Table 4) to the lower asymptotic performance, which was due to the difficulty of the task. Nevertheless, clear primacy and recency effects without concomitant low variances can be shown to emerge when the data for all the trained rats are analyzed (Kesner et al., 1984) or when the rats are postsurgically retrained without the use of a criterion. Finally, variances that are significantly lower than those expected by chance are not always observed, even when the rats are trained to a criterion. It should be noted that part of the difficulty in learning the order-recognition memory task is due to the requirement of selecting serially adjacent items to generate a serial-position curve. When one uses a temporal lag of two or more intervening items in the study phase, then order-recognition memory performance is markedly improved (Kesner, 1990).

To our knowledge there have been no other published studies on rats that have been tested for primacy and recency effects for order-recognition memory of lists of spatial locations. Maki et al. (1984) tested rats for order memory by comparing performance on the first versus the last items in a list, excluding middle items. Thus, they did not use a testing procedure that allowed for an analysis of primacy and recency effects.

Should one train animals to a specific criterion of performance, or present a fixed number of trials in order to examine specific psychological functions? The answer depends upon one's interest. Given a primary interest in determining whether rats can demonstrate a primacy effect 
in list-learning experiments, the selection of a fixed number of trials is appropriate. Given a primary interest in investigating primacy effects, their maintenance, and their underlying neural circuits, then the selection of a fixed number of acquisition trials could easily result in the absence of primacy effects due to floor or ceiling effects. In order to avoid the absence of primacy effects, it is more appropriate to train all the subjects to a fixed performance criterion prior to brain manipulation, although this procedure may reduce the variance. However, it is also important that a postoperative control group receive a fixed number of trials rather than be retrained to a criterion, in order to evaluate the maintenance of primacy and recency effects. In general, our results have indicated that the control groups continued to display primacy and recency effects in both item- and order-recognition memory paradigms with variances that were generally appropriate.

In summary, it appears clear that rats do display primacy and recency effects in list-learning experiments for both item- and order-recognition memory for spatial location information.

\section{REFERENCES}

Bolhuis, J. J., \& VAN KAMPEN, H. S. (1988). Serial position curves in spatial memory of rats: Primacy and recency effects. Quarterly Journal of Experimental Psychology, 40B, 135-159.

Cole, S., Hainsworth, F. R., Kamil, A. C., Mercier, T., \& Wolf, L. L. (1982). Spatial learning as an adaptation in hummingbirds. Science, 217, 655-657.

Dimattia, B. V., \& KesNer, R. P. (1984). Serial position curves in rats: Automatic versus effortful information processing. Journal of Experimental Psychology: Animal Behavior Processes, 10, 557-563.

Gaffan, E. A. (1992). Primacy, recency, and the variability of data in studies of animals' working memory. Animal Leaming \& Behavior, 20, 240-252.

GaffaN, E. A., \& Davies, J. (1981). The role of exploration in winshift and win-stay performance on a radial maze. Learning \& Motivation, 12, 282-299.

Harper, D. N., Dalrymple-Alford, J. C., \& Mclean, A. P. (1992). Production of a serial position effect in rats using a 12-arm radial maze. Journal of Neuroscience Methods, 44, 197-207.
Harper, D. N., Dalrymple-Alford, J. C., \& Mclean, A. P. (1993). The effect of medial septal and mammillary body lesions on the serial position curve in rats. Psychobiology, 21, 130-138.

HASHER, L., \& ZACKS, R. T. (1979). Automatic and effortful processes in memory. Journal of Experimental Psychology: General, 108, 356-388.

Johnson, D. L., \& Kesner, R. P. (in press). The effects of lesions of the entorhinal cortex and the horizontal nucleus of the diagonal band of broca upon performance of a spatial location recognition task. Behavioural Brain Research.

KESNER, R. P. (1990). New approaches to the study of comparative cognition (Monograph No. 97, pp. 22-36). Washington, DC: U.S. Department of Health and Human Services, National Institute on Drug Abuse: Alcohol, Drug Abuse, and Mental Health Administration.

Kesner, R. P., Crutcher, K. A., \& BeERS, D. (1988). Serial position curves for item (spatial location) information: Role of the dorsal hippocampus and medial septum. Brain Research, 454, 219-226.

Kesner, R. P., Crutcher, K. A., \& Measom, M. O. (1986). Medial septal and nucleus basalis magnocellularis lesions produce order memory deficits in rats which mimic symptomatology of Alzheimer's disease. Neurobiology of Aging, 7, 287-295.

Kesner, R. P., Crutcher, K. A., \& Omana, H. (1990). Memory deficits following nucleus basalis magnocellularis lesions may be mediated through limbic, but not neocortical, targets. Neuroscience, 38, 93-102.

KesNer, R. P., \& Holbrook, T. (1987). Dissociation of item and order spatial memory in rats following medial prefrontal cortex lesions. Neuropsychologia, 25, 653-664.

Kesner, R. P, Measom, M. O., Forsman, S. L., \& Holbrook, T. H. (1984). Serial-position curves in rats: Order memory for episodic spatial events. Animal Learning \& Behavior, 12, 378-382.

MaKi, W. S., BeATTY, W. W., \& Clouse, B. A. (1984). Item and order information in spatial memory. Journal of Experimental Psychology: Animal Behavior Processes, 10, 437-452.

Olton, D. S., Handlemann, G. E., \& Walker, J. A. (1981). Spatial memory and food searching strategies. In A. C. Kamil \& T. D. Sargent (Eds.), Foraging behavior: Ecological, ethological, and psychological approaches (pp. 333-354). New York: Garland STPM Press.

Olton, D. S., \& Schlosberg, P. (1978). Food searching strategies in young rats: Win-shift predominates over win-stay. Journal of Comparative \& Physiological Psychology, 92, 609-618.

Roberts, W. A., \& SMYTHE, W. E. (1979). Memory for lists of spatial events in the rat. Learning \& Motivation, 10, 313-336.

(Manuscript received March 10, 1993; revision accepted for publication September 7, 1993.) 